\title{
Identification of MRF4: a new member of the muscle regulatory factor gene family
}

\author{
Simon J. Rhodes and Stephen F. Konieczny ${ }^{1}$ \\ Department of Biological Sciences, Purdue University, West Lafayette, Indiana 47907
}

\begin{abstract}
We have identified a rat cDNA encoding MRF4, a new member of the muscle regulatory factor gene family that includes MyoD1, myogenin, and Myf-5. MRF4 encodes a predicted 27-kD protein that contains a conserved helix-loop-helix motif, which is a common feature of this gene family. Northern analyses indicate that MRF4 is expressed solely in skeletal muscle tissue but is not detected in most embryonic muscle cell lines.

Transfection of MRF4 into C3H10T1/2 fibroblasts produces stable myogenic lineages at frequencies that are equal to or greater than those obtained when MyoD1 or myogenin are introduced into these cells. Expression of the MRF4 cDNA leads to expression of the endogenous MyoD1 and myogenin genes, although C3H10T1/2 cells expressing MyoD1 or myogenin cDNAs do not express MRF4. Interestingly, the endogenous MyoD1 and myogenin genes are negatively regulated by serum and by purified growth factors since MRF4-transfected C3H10T1/2 cells activate MyoD1 and myogenin expression only in mitogen-depleted, differentiation-induced muscle cultures. The myofiber-specific expression pattern of MyoD1 and myogenin in these cells suggests that the primary role for this muscle regulatory factor gene family may be in regulating specific terminal differentiation events that are crucial for normal skeletal muscle development.
\end{abstract}

[Key Words: MRF4; muscle regulatory factor; MyoD1; myogenin; Myf-5: C3H10T1/2 cells]

Received September 1, 1989; revised version accepted October 11, 1989

Skeletal myogenesis is characterized by a series of discrete developmental events that regulate the establishment of stable stem cell lineages (determination), the expression of specific structural genes (differentiation), and the specialization of the contractile unit (maturation). Recent studies have begun to dissect the underlying molecular mechanisms that control each of these events, including the characterization of cis/trans-regulatory elements that control the initial activation and subsequent modulation of the contractile protein gene set. In addition, exciting progress has been made recently in identifying specific muscle regulatory factors that are likely involved in both determination and differentiation decisions.

The identification of muscle regulatory factors has been aided greatly by studying the unique properties associated with the mouse embryonic cell line, C3H10T1/ 2 (Reznikoff et al. 1973). Taylor and Jones $(1979,1982$ ) demonstrated that incorporation of the cytosine analog, 5-azacytidine, into replicating C3H10T1/2 cells results in the conversion of these cells to muscle, fat, and cartilage phenotypes. These early observations suggested that distinct regulatory genes, which presumably are inactive in C3H10T1/2 cells, become transcriptionally active after 5-azacytidine treatment. Additional studies

${ }^{1}$ Corresponding author. demonstrated that the conversion event produces lineage-specific stem cells that maintain their undifferentiated phenotype in a stable heritable fashion, but are induced to terminally differentiate in an appropriate culture environment (Chapman et al. 1984; Konieczny and Emerson 1984). The high conversion frequencies (up to $50 \%$ ) suggested to Emerson and colleagues that activation of one or several determination loci was sufficient to convert embryonic precursor cells to stable determined cell lineages (Konieczny and Emerson 1984).

The simplicity of the determination loci model permitted a direct test of its validity using genomic DNA transfections. In these experiments, genomic DNA from mouse or quail myoblasts was transfected into C3H10T1/2 cells and the subsequent colonies examined for myogenic phenotypes. Myogenic colonies were obtained in $\sim 1$ out of 6000 transfectants, which is the expected frequency if a single genetic locus is involved in the conversion of multipotential C3H1OT1/2 cells to a myogenic lineage (Konieczny et al. 1986; Lassar et al. 1986). No myogenic colonies were obtained when control C3H10T1/2 DNA was tested. Subsequent experiments by Davis et al. (1987), using a cDNA subtractive hybridization approach, and Pinney et al. $(1988,1989)$, using a selectable human cosmid genomic library, were crucial in identifying two myogenic regulatory genes, MyoDl and myd, that produced myogenic colonies after 
transfection into C3H10T1/2 cells. Although the myd gene has yet to be characterized at the nucleotide level, it is distinct from the MyoD1 gene. In addition, because myd transfectants activate the expression of the endogenous MyoDl gene, it was suggested that myd may code for an early gene product in a dependent regulatory pathway that is operative during myogenic determination and differentiation (Pinney et al. 1988, 1989).

The characterization of the MyoDl gene product has prompted other investigators to examine whether additional myogenic regulatory factors function in developing skeletal muscle cells. Wright et al. (1989), as well as Edmondson and Olson (1989), independently isolated cDNA clones from rat and mouse skeletal muscle cell lines, respectively, that code for the muscle regulatory factor myogenin. Expression of myogenin, like MyoDl and myd, converts $\mathrm{C} 3 \mathrm{H} 10 \mathrm{~T} 1 / 2$ cells to stable myogenic cell lineages. A similar study from Braun et al. (1989) has resulted in the isolation of Myf- 5 , a muscle regulatory factor that also produces myogenic lineages when expressed in C3H10T1/2 cells. In addition, Lin et al. (1989) recently isolated a muscle regulatory factor cDNA, designated CMD1. Sequence and Southern hybridization analyses, however, indicate that CMD1 likely is encoded by the chicken MyoDl gene. Most importantly, these studies have demonstrated that MyoD1, myogenin, and Myf- 5 share a region of extensive protein similarity, the basic/myc-like domain. This region has been shown by Tapscott et al. (1988) to be the functional domain of MyoD1, mediating the conversion of fibroblasts to myogenic cell types.

The similarity of MyoD1, myogenin, and Myf-5 suggests that the establishment of a stable myogenic cell lineage may require the coordinated expression of multiple members of a muscle regulatory factor gene family. At the present time, the individual role(s) of these distinct gene products in normal muscle development remains elusive. Myogenin and MyoD1 are expressed very early in development, with the first detectable transcripts being identified in embryonic somite and limb bud tissues (Wright et al. 1989; Sassoon et al. 1989). Likewise, Myf-5 appears to be expressed early in development, as it is detected in fetal skeletal muscle (Braun et al. 1989). To investigate whether additional, uncharacterized members of this gene family function in adult muscle, we screened a cDNA library derived from adult rat skeletal muscle mRNA with a MyoD1 probe under low stringency hybridization conditions. Our results demonstrate that MyoD1-like mRNAs are expressed in adult musculature. In this report we describe the properties of one particular cDNA clone, designated Muscle Regulatory Factor 4 (MRF4).

MRF4 encodes a predicted $27-\mathrm{kD}$ protein that contains the conserved basic/myc-like domain common to MyoD1, myogenin, and Myf-5. Southern hybridizations and DNA sequence analyses demonstrate that MRF4 represents a unique gene that is part of the MyoD1, myogenin, and Myf-5 family of muscle regulatory factors. Northern hybridizations indicate that MRF4 is expressed solely in skeletal muscle tissue but is not de- tected in most embryonic skeletal muscle cell lines, including 23A2, C2C12, Sol8, L6, and L8. Interestingly, MRF4 is able to convert C3H10T1/2 cells to stable myogenic lineages at frequencies that are equal to or greater than those obtained when MyoD1 or myogenin is introduced into these cells. In addition, cells expressing MRF4 activate the expression of the endogenous MyoD1 and myogenin genes, whereas cells expressing MyoDl or myogenin cDNAs do not express MRF4. Our studies suggest that a muscle regulatory factor gene family operates in a coordinated fashion to control the developmental decisions that are required for the generation and maintenance of the skeletal muscle lineage.

\section{Results}

Isolation of a cDNA clone encoding the muscle regulatory factor MRF4

The cDNAs derived from the muscle-specific regulatory genes MyoD1 (Davis et al. 1987; Lin et al. 1989), myogenin (Edmondson and Olson 1989; Wright et al. 1989), and Myf-5 (Braun et al. 1989) encode a conserved basic protein domain that also exhibits similarity to a region of the myc family of oncoproteins. Tapscott et al. (1988) have demonstrated that expression of the MyoDl basic/ myc-like domain in multipotential C3H10T1/2 cells is sufficient to convert these cells to stable myogenic lineages, indicating that the conserved region in MyoD1, myogenin, and Myf-5 plays a central role in how these regulatory genes function. Although each of these genes is expressed early in development, there is some evidence that each is also involved in regulating terminal differentiation events (Braun et al. 1989; Edmondson and Olson 1989; Lin et al. 1989; Weintraub et al. 1989). This possibility suggested to us that a muscle regulatory factor gene family may exist in which different genes are utilized at different developmental times for fetal versus adult skeletal muscle regulation. To examine whether related but distinct regulatory gene products operate predominantly in adult skeletal muscle tissue, a $\lambda$ gt 10 cDNA library derived from adult rat skeletal muscle fibers was screened using a mouse MyoDl cDNA probe (for details, see Materials and methods). One particular isolate, designated $\lambda M R F 4$, was chosen for further analysis.

The complete nucleotide and deduced amino acid sequences of this cDNA are shown in Figure 1A. $\lambda$ MRF4 contains a 1296-bp insert that has a single major open reading frame encoding a putative 242 amino acid protein with a predicted molecular mass of $\sim 27 \mathrm{kD}$. The proposed translation start site (GAACATGA) contains a potential vertebrate consensus translation initiation sequence (Cavener 1987; Kozak 1987) and is followed by two additional methionine codons. The MRF4 insert also contains a 44-bp 5'-untranslated leader sequence and a 526-bp 3'-untranslated region containing a slightly altered polyadenylation recognition sequence (ATTAAAA) and 26 adenine residues. Identical polyadenylation signals are known to be utilized by other genes 

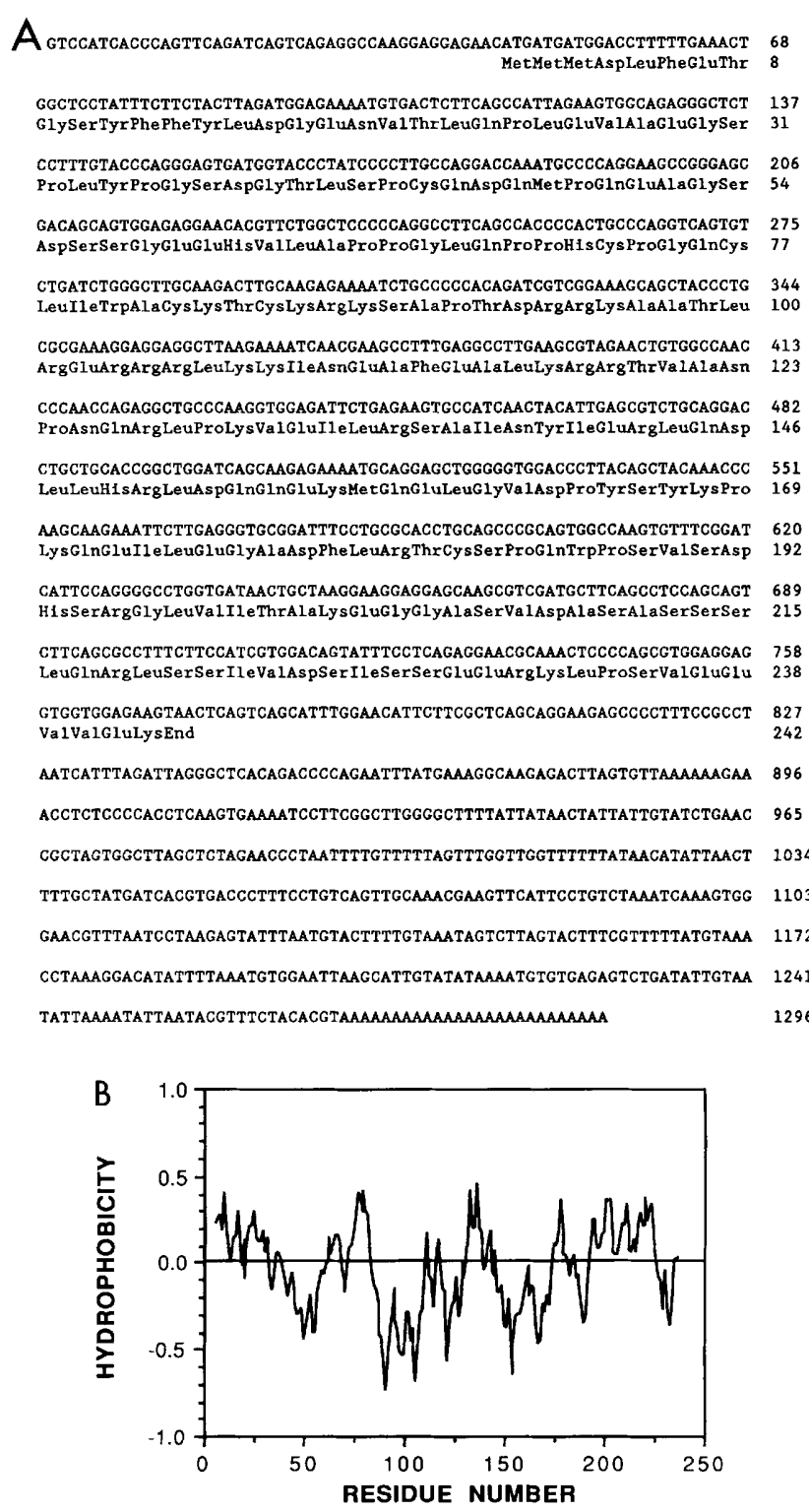

Figure 1. MRF4 sequence. $(A)$ Nucleotide and predicted amino acid sequence of the rat MRF4 cDNA. $(B)$ Hydropathy plot of the deduced MRF4 protein. The Kyte and Doolittle Algorithm (Kyte and Doolittle 1982) was used to produce the computergenerated hydropathy plot. Each point on the curve represents the average hydropathy across an 11 amino acid window at each residue position. Values are given on a hydophobicity scale: Positive values represent hydrophobic positions and negative values represent hydrophilic positions.

(Jung et al. 1980). Primer extension analysis has revealed that the endogenous MRF4 mRNA contains an additional 35-45 nucleotides, $5^{\prime}$ to our +1 nucleotide position (S. Rhodes and S. Konieczny, unpubl.). In addition, preliminary sequence data from a MRF4 genomic clone indicate that the methionine codon at +45 of the isolated cDNA likely represents the true translation start site (S. Rhodes and S. Konieczny, in prep.). Comparative sequence analysis has demonstrated that MRF4 contains amino acid regions similar to regions within $M y o D 1$ and c-myc, confirming that MRF4 is related to the MyoD1, myogenin, and Myf- 5 family of muscle regulatory genes (see below).

A computer-generated hydropathy plot using the predicted MRF4 amino acid sequence indicates that MRF4 encodes a highly charged protein (Fig. 1B). For example, whereas the amino terminus is acidic (amino acids 4-60), the central portion of the MRF4 protein encodes a basic domain (amino acids 86-108) that is part of the conserved basic/myc-like region found in MyoD1, myogenin, and Myf-5 (see below). The carboxyl terminus (amino acids 207-235) of MRF4 contains a large number of serine residues, some of which may serve as potential phosphorylation sites. MRF4 does not contain an obvious leucine zipper motif (Landschulz et al. 1988), although the internal basic/myc-like region has the potential of forming a helix-loop-helix (HLH) structure, which has been implicated in DNA binding and protein dimerization functions (Murre et al. 1989a,b). At this time, we do not know whether any of these structural features plays a significant role in the biological activity of MRF4.

To confirm that MRF4 represents a novel cDNA clone and is distinct from rat MyoD1, myogenin, and Myf-5, a series of Southern hybridizations were performed using rat genomic DNA and MRF4, MyoDl, and myogenin cDNA probes. As shown in Figure 2, MRF4, MyoD1, and myogenin each hybridize to a unique set of restriction fragments. Southern hybridizations using human DNA and MRF4 as a probe also produced different hybridization patterns from those reported for Myf-5 (Braun et al. 1989; data not shown). In addition, using high stringency Southern hybridization analyses, we have found that the mouse genome contains a MRF4 gene that is distinct from the mouse MyoDl and myogenin loci /data not shown). Hybridization of MRF4 probes to DNA from



Figure 2. MRF4, MyoDl, and myogenin cDNAs are encoded by different genes. Rat genomic DNA was restricted with the indicated enzymes and hybridized to either MRF4, MyoD1, or myogenin cDNA probes (see Materials and methods). The migration of DNA size markers (in kilobases) is indicated. Each probe hybridizes to a distinct pattern of restriction fragments, demonstrating that each cDNA is transcribed from a separate gene. 
myd-containing cell lines also has revealed that MRF4 is not the rat homolog of myd (S.H. Pearson-White and C.P. Emerson, Jr., pers. comm.). We conclude from these DNA sequence and Southern hybridization analyses that MRF4 represents a novel gene that is distinct from the muscle regulatory genes MyoD1, myogenin, Myf-5, and myd.

\section{MRF4 expression is restricted to skeletal muscle}

To determine whether MRF4 represents a muscle-specific gene product, we examined MRF4 mRNA levels in C 3 H10T $1 / 2$ cells and in a number of embryonic muscle cell lines that were induced to differentiate. Included in this analysis were the mouse cell lines 23A2, $\mathrm{C} 2 \mathrm{Cl} 2$, and Sol8, the rat cell lines L6, L6)1-C, L8, and L8E63, and the nonfusing mouse myogenic cell line $\mathrm{BC} 3 \mathrm{H} 1$. Each of these myogenic lines differentiate in low mitogen medium and express a number of contractile protein genes, including myosin heavy chain (data not shown), fast troponin I (TnI), and slow TnI (Fig. 3A). Expression of MRF4 mRNA was not detected in any of the cell lines under normal conditions. Extended exposure of these Northern blots was required to reveal a very weak, 1.5-kb MRF4 signal in the L6 subclone L6J1-C (Fig. 3A). The possibility that MRF4 may be expressed transiently during myogenesis, as has been reported for myogenin (Edmondson and Olson 1989; Wright et al. 1989 |, was also examined. For these studies, 23A2 myoblasts were induced to differentiate and RNA was isolated from day ${ }^{-1}$ through day ${ }^{+} 6$. Again, MRF4 transcripts were not detected throughout this 8 -day period (data not shown).

The inability to detect MRF4 mRNA in a variety of embryonic myogenic cell lines suggested to us that either MRF4 is not expressed in muscle cells or that MRF4 encodes a predominantly adult gene product. To distinguish these possibilities, total RNA from adult rat tissues was examined for MRF4 expression. As shown in Figure 3B, MRF4 mRNA is abundant in a number of adult skeletal muscle fiber types, including the predominantly fast twitch plantaris and gastrocnemius, as well as in the predominantly slow twitch soleus. No detectable MRF4 mRNA was observed in cardiac (heart) or smooth (stomach) muscle tissues. We were also unable to detect MRF4 expression in nonmuscle tissue types, including liver, kidney, testis, brain, and lung. MRF4 exhibits the same tissue specificity as the muscle regula-


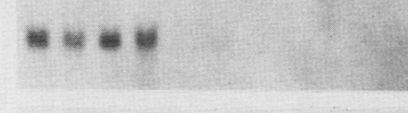

MRF4

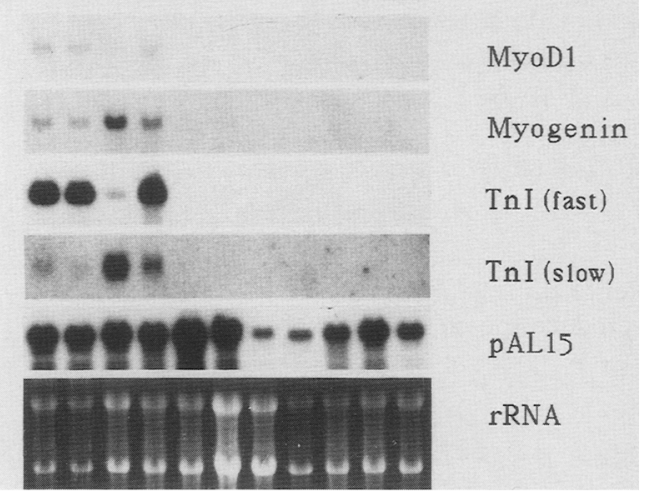

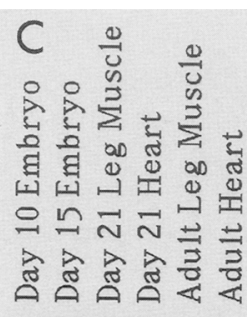



MRF 4

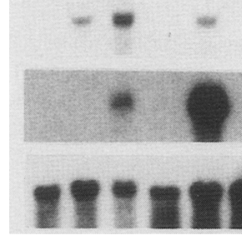

Myogenin

$\operatorname{TnI}$ (fast)

pAL15

Figure 3. Expression patterns of the MRF4 mRNA. (A) Expression of MRF4 in cultured myogenic cell lines. Total RNA from differentiated myofiber (MF) or myocyte (MC) cultures was hybridized to MRF4 or fast/slow skeletal TnI probes (see Materials and methods|. After hybridization, Northern blots were stripped and rehybridized with the control pAL15 probe. The pAL15 gene has been shown to be constitutively expressed in most cell types (Bernlohr et al. 1984, 1985; Vaidya et al. 1989). Note that MRF4 mRNA is detected only in L6J1-C RNA, following prolonged exposure of the Northern blot. (B) MRF4 expression is restricted to adult skeletal muscle tissues. RNA from adult rat tissues was hybridized to MRF4, MyoD1, myogenin, fast/slow TnI, and pAL15 probes. Plantaris and gastrocnemius are predominantly fast twitch leg muscles, whereas soleus is predominantly a slow twitch muscle. The pAL15 transcript is downregulated in liver and kidney tissues; therefore, a photograph of the ethidium bromide-stained gel showing the $28 \mathrm{~S}$ and $18 \mathrm{~S}$ rRNAs is included. MRF4 expression is detected only in skeletal muscle tissues. $(C)$ Northern analysis indicates that the MRF4 transcript appears late in development. Total RNA was isolated from whole rat embryos (days 10 and 15), day-21 embryonic leg and heart muscle, and adult leg and heart muscle. Northern analysis was performed as above with MRF4, myogenin, fast TnI, and control pAL15 probes. Although myogenin appears by day 15 of development, extended exposures are required to detect MRF4 mRNA in day-21 leg muscle. 
tory genes MyoD1 and myogenin, although we estimate from the intensity of our Northern signals that MRF4 mRNA is more abundant than either MyoD1 or myogenin mRNA in adult rat skeletal muscle. MRF4 mRNA is present at equivalent levels in both fast and slow skeletal muscles, whereas myogenin mRNA appears to be enriched in soleus and MyoDl mRNA is more abundant in plantaris and gastrocnemius. In separate studies, we also examined MRF4 expression in RNA extracted from mouse tissues. In all cases, an MRF4 mRNA of $\sim 1.5-\mathrm{kb}$ was detected only in mouse skeletal muscle RNA samples (data not shown), demonstrating that expression of the mouse MRF4 homolog similarly is restricted to skeletal muscle lineages.

Although MRF4 is expressed in the adult, it is conceivable that the MRF4 gene is also expressed early in development. To address this possibility, RNA was isolated from day-10, -15 and, -21 rat embryos and analyzed for MRF4 expression. MRF4 was not detected in day-10 and day-15 whole-embryo RNA but was detected in day-21 leg muscle RNA, which correlates with the expression of the fast TnI gene in these samples (Fig. 3C). In addition, day-21 heart did not contain detectable levels of MRF4, suggesting that unlike a number of other skeletal muscle-specific gene products, including skeletal $\alpha$-actin (Ordahl 1986; Sassoon et al. 1988), MRF4 is not expressed in embryonic heart tissue. Although we did not detect MRF4 expression until day 21 of development, myogenin transcripts were readily detected in day-15 embryonic RNA. Similar myogenin expression patterns have been reported by Wright et al. (1989), demonstrating that the MRF4 and myogenin genes are not temporally coregulated during development. It should be noted that these studies do not rule out the possibility that MRF4 may be expressed at a very early stage of embryogenesis. Our results, however, do provide evidence that MRF4 expression is restricted to a skeletal muscle lineage in late fetal and adult animals.

\section{Expression of MRF4 converts C3H10T1/2 cells to stable myogenic lineages}

MRF4 is expressed predominantly in adult skeletal muscle tissues and, unlike MyoD1 and myogenin, is not detected in most established skeletal muscle cell lines. MRF4, however, shows sequence similarity to MyoDl, myogenin, and Myf-5 (see below), suggesting that it may be part of a larger gene family that is involved in a number of regulatory processes associated with skeletal muscle development. To begin understanding how MRF4 functions during skeletal myogenesis, the MRF4 cDNA was subcloned into the eukaryotic expression vector pEMSVscribe 2 (Davis et al. 1987). C3H10T1/2 cells were transfected transiently with MRF4 or with a pEMSVscribe 2 vector containing the MyoD1 or myogenin cDNAs. Transfection of MRF4 produced a very large number $(\sim 4 \%)$ of differentiated myogenic cells that fused into multinucleated muscle fibers and expressed myosin heavy chains (Fig. 4). Similar results were obtained when the MyoD1 and myogenin expression vectors were introduced into $\mathrm{C} 3 \mathrm{H} 10 \mathrm{~T} 1 / 2$ cells, al-



Figure 4. Expression of MRF4 converts C3H10T1/2 fibroblasts to stable myogenic lineages. Antimyosin immunocytochemistry of $\mathrm{C} 3 \mathrm{H} 10 \mathrm{~T} 1 / 2$ cells following transient transfection with control $(A)$, MRF4 $(B)$, MyoDl $(C)$, and myogenin $(D)$ expression vectors. Also shown are phase-contrast photomicrographs of the C3H10T1/2 MRF4-\#7 stable cell line as myoblasts $(E)$ and as differentiated myofibers $(F)$ (see text for details).

though myogenin consistently produced fewer differentiated muscle cells than MRF4 or MyoDl in these transient assays. No myogenic cells were detected in control cultures transfected with the pEMSVscribe 2 vector or with antisense MRF4 gene constructs.

The ability of MRF4 to convert fibroblasts to skeletal muscle cells is not limited to the multipotential C3H10T1/2 cell line because NIH-3T3 and BALB/c-3T3 cells express skeletal myosin when transfected with the MRF4 cDNA (data not shown). Differentiation-defective 23A2 pT24-9a2 cells (Konieczny et al. 1989), which constitutively express an activated H-ras gene and proliferate in suspension cultures, also are converted to myosin-expressing cells by MRF4 (data not shown). The dominance of the MRF4 gene product is particularly interesting, since the presence of an activated $\mathrm{p} 21$ protein in myogenic cell lines abolishes expression of the endogenous MyoDl and myogenin genes (Konieczny et al. 1989; Lassar et al. 1989a). It is clear, however, that the myogenic conversion phenomenon is restricted to particular embryonic cell types. Transfected $\mathrm{HeLa}$ and COS-1 cells do not express skeletal myosin under similar experimental conditions (data not shown).

Cotransfections using MRF4 and a selectable neomycin-resistance gene demonstrate that MRF4 can convert C3H10T1/2 cells to stable myogenic lineages. Up to $83 \%$ of the G418-resistant, MRF4-transfected C3H10T1/2 colonies fuse and form large networks of muscle fibers that stain positively for myosin heavy chain expression (Table 1). Similar myogenic conversion is obtained when MyoDl and myogenin are introduced 
Table 1. Myogenic conversion of C3H1OT1/2 cells following stable transfection with muscle regulatory factor expression vectors

\begin{tabular}{lccc}
\hline $\begin{array}{l}\text { Muscle } \\
\text { regulatory } \\
\text { gene }\end{array}$ & $\begin{array}{l}\text { Number of } \\
\text { myogenic } \\
\text { colonies }\end{array}$ & $\begin{array}{l}\text { Total } \\
\text { number of } \\
\text { colonies }\end{array}$ & $\begin{array}{l}\text { Myogenic } \\
\text { conversion } \\
(\%)\end{array}$ \\
\hline Control & 0 & 429 & 0 \\
MRF4 & 627 & 757 & 83 \\
MyoD1 & 209 & 357 & 59 \\
Myogenin & 275 & 386 & 71 \\
\hline
\end{tabular}

C3H10T1/2 cultures were cotransfected stably with pKO-neo and with a control plasmid or with pEMSVscribe 2 containing MRF4, MyoD1, or myogenin cDNAs. After 2 weeks of growth, colonies were induced to differentiate for $48 \mathrm{hr}$ in ITS medium, they were fixed and stained with Giemsa, and the percentage of myogenic colonies was determined. MRF4, MyoD1, and myogenin cDNAs convert C3H10T1/2 fibroblasts to myogenic lineages at high frequencies.

into these cells. Because of these high conversion frequencies, we were able to isolate stable C3H10T1/2 clones that constitutively express transfected MRF4, MyoD1, or myogenin cDNAs. Each of these clones can be maintained as undifferentiated myoblasts in medium containing high concentrations of serum or, after mitogen removal, can be induced to fuse and biochemically differentiate (Fig. 4). We conclude that the MRF4 gene exhibits a very different expression pattern compared to the MyoD1 and myogenin loci, yet functions in a similar fashion to MyoD1, myogenin, and Myf-5 in converting $\mathrm{C} 3 \mathrm{H} 10 \mathrm{~T} 1 / 2$ cells to myogenic lineages.

\section{C3H10T1/2 cells expressing MRF4 also express MyoD1 and myogenin}

The isolation of stable C3H10Tl/2 cell lines expressing MRF4, myogenin, or MyoD1 cDNAs permitted an examination of the potential interactions between each of these muscle regulatory factors. Myoblast and myofiber RNA from each converted C3H1OT1/2 cell line was isolated and analyzed for the expression of several genes, including the endogenous MRF4, MyoDl, and myogenin loci. C3H10T1/2 cells expressing the rat MRF4 cDNA (C3H10T1/2 MRF4-\#7) expressed high levels of myosin heavy chains (data not shown), fast and slow TnI mRNA, and the endogenous myogenin and MyoD1 genes (Fig. 5). Myogenin is regulated appropriately in C3H10T1/2 MRF4-\#7 cells, because its expression parallels that in the 23A2 myogenic cell line, showing an increase during the initial decision of myoblasts to morphologically and biochemically differentiate. Surprisingly, C3H10T1/2 MRF4-\#7 cells express MyoD1 only in cultures containing differentiated muscle fibers. We have not detected MyoD1 expression in proliferating, undifferentiated C3H10T1/2 MRF4-\#7 cells, even though MyoDl expression is evident in both myoblast and myofiber cultures of the control 23A2 (Fig. 5) and C2C12 myogenic cell lines (Vaidya et al. 1989). Identical results have been obtained with pooled C3H10T1/2 MRF4 colonies.

To examine whether the endogenous MRF4 gene is expressed in response to transfected MyoD1 and myogenin cDNAs, C3H10T1/2 MyoD1-\#8 and C3H10T1/2 myogenin-\# 1 clonal lines were examined for expression of additional regulatory gene products. As shown in Figure 5, C3H10T1/2 MyoDl-\#8 expresses high levels of myogenin but does not express detectable levels of MRF4. C3H10T1/2 myogenin-\#1 cells also do not express MRF4 mRNA, although the endogenous MyoD1 gene is transcriptionally activated. Interestingly, these cells, like C3H10T1/2 MRF4-\#7, express MyoD1 exclusively in myofiber cultures. It is intriguing to speculate that this pattern of MyoDl expression may reflect the true in vivo transcriptional regulation of this gene, as previous studies from our laboratory demonstrated that the endogenous MyoDl gene is negatively regulated when cells are maintained as proliferating myoblasts in high growth factor conditions (Vaidya et al. 1989). We conclude from these studies that although MRF4 is able to induce expression of the MyoDl and myogenin genes, neither MyoDl nor myogenin can activate expression of the mouse MRF4 gene. The possibility that specific



Figure 5. C3H10T1/2 cells expressing a transfected MRF4 cDNA express the endogenous MyoDl and myogenin genes. RNAs from representative clones of $\mathrm{C} 3 \mathrm{H} 10 \mathrm{~T} 1 / 2$ cells transfected stably with MRF4, MyoD1, or myogenin expression vectors were hybridized to cDNA probes as described in Fig. 3. RNA was extracted from both myoblast $(B)$ and myofiber $(F)$ cultures. RNA samples from 23A2 myoblasts (B), 23A2 myofibers $(\mathrm{F})$, and proliferating $(\mathrm{P})$ and confluent $(\mathrm{C}) \mathrm{C} 3 \mathrm{H} 10 \mathrm{~T} 1 / 2 \mathrm{fi}-$ broblasts were included as controls. Membranes were rehybridized with probes recognizing the pAL15 constitutive transcript. Note that the MRF4-expressing line and pool population express the endogenous MyoDl and myogenin genes, whereas MyoD1 and myogenin cDNA expression does not lead to the detection of MRF4 transcripts. 
feedback mechanisms are involved in controlling the expression of these muscle regulatory factors currently is being investigated.

Fibroblast growth factor regulates MyoD1, myogenin, and terminal differentiation in the presence of constitutive MRF4 expression

Our laboratory has demonstrated previously that MyoD1 transcription and terminal differentiation are corepressed when cells are maintained in the presence of purified fibroblast growth factor (FGF) (Vaidya et al. 1989). We were interested in establishing whether FGF could suppress the differentiation of the C3H10T1/2 MRF4-\#7 cell line, since constitutive MRF4 expression leads to the activation of the endogenous MyoDl and myogenin genes. Although FGF treatment does not alter MRF4 or pAL15 mRNA levels, FGF blocks muscle fiber formation and the expression of the TnI and myosin heavy chain genes (Fig. 6). This repression can be reversed, because removal of FGF rapidly restores contractile protein gene expression and myoblast fusion within $24 \mathrm{hr}$. The endogenous MyoDl and myogenin mRNAs are not expressed in the FGF-treated cultures but return to control levels after removing FGF (Fig. 6). Although constitutive MRF4 expression is sufficient to activate (either directly or indirectly) the MyoDl and myogenin loci, these regulatory genes remain responsive to exogenously supplied growth factors. Additional studies are required to determine whether the endogenous MRF4 genes similarly are regulated by these environmental factors.

\section{Discussion}

We isolated a novel rat cDNA clone (MRF4) that is capable of converting fibroblasts to stable determined myogenic stem cells at a very high frequency $(\geqslant 80 \%)$. Cells expressing MRF4 can be maintained as undifferentiated myoblasts or, after mitogen depletion, are induced to terminally differentiate and express the normal complement of muscle-specific gene products. MRF4 mRNA is expressed predominantly in adult skeletal muscle, in both slow and fast twitch fibers. Late fetal and adult heart muscle, smooth muscle, liver, kidney, testis, brain, and lung tissues do not contain detectable levels of MRF4 mRNA.

MRF4 represents the fourth member of a structurally and functionally related family of muscle regulatory factors that includes MyoD1 (Davis et al. 1987; Lin et al. 1989), myogenin (Edmondson and Olson 1989; Wright et al. 1989), and Myf-5 (Braun et al. 1989). A fifth myogenic regulatory gene, myd, has also been described (Pinney et al. 1988, 1989), although at this time it is not known whether myd is related directly to this same family of genes. MRF4, MyoD1, and myogenin exhibit distinct expression patterns and different abilities to activate the endogenous regulatory genes, although each, in addition to Myf-5 and myd, appears to function in a similar fashion. Independent transfections of C3H10T1/2 cells



Figure 6. Expression of the MyoDl and myogenin regulatory factor mRNAs is regulated by FGF in C3H10T1/2 MRF4-\#7 cells. Control C3H10T1/2 MRF4-\#7 cells were treated with the differentiation medium heparin/ITS (HITS) plus $5 \%$ horse serum (HS) for $48 \mathrm{hr}$ (Vaidya et al. 1989). FGF cultures were fed HITS and $5 \%$ HS containing $10 \mathrm{ng} / \mathrm{ml} \mathrm{FGF}$ for $48 \mathrm{hr}$, at which time RNA was harvested or duplicate cultures were switched back to HITS and 5\% HS for an additional $24 \mathrm{hr}$. 23A2 myofiber (MF) RNA served as a control. RNA from each group was hybridized to muscle regulatory factor, TnI and pAL15 probes, as described in Fig. 3. Inhibition of myogenesis by FGF occurs in the presence of MRF4 transcription and is associated with the downregulation of the MyoDl, myogenin, and contractile protein genes.

with each gene establish a regulatory control system that is responsive to serum growth factors and mediates terminal differentiation events.

One of the unique features of the muscle regulatory factor gene family is that the four genes encode proteins that share a striking similarity in three specific regions (see Fig. 7). Within the conserved basic/myc-like domain I of all four proteins (MRF4 amino acids 77-149), 52 out of 73 amino acid residues are identical. Of the 21 substitutions, only 7 positions code for a different amino acid in each of the four gene products. A second conserved amino acid region (II) that contains 9 identical amino acid residues is shared by MyoD1 and Myf-5 (Braun et al. 1989). This region, however, is not found in MRF4 or in myogenin. Finally, region III (MRF4 amino acids 214-228), comprising 15 carboxyl residues, is common to the MRF4, MyoD1, and Myf-5 gene products but, again, is not encoded by the myogenin protein. The functional significance of each conserved and divergent amino acid region encoded by these muscle regulatory factors remains to be determined. 


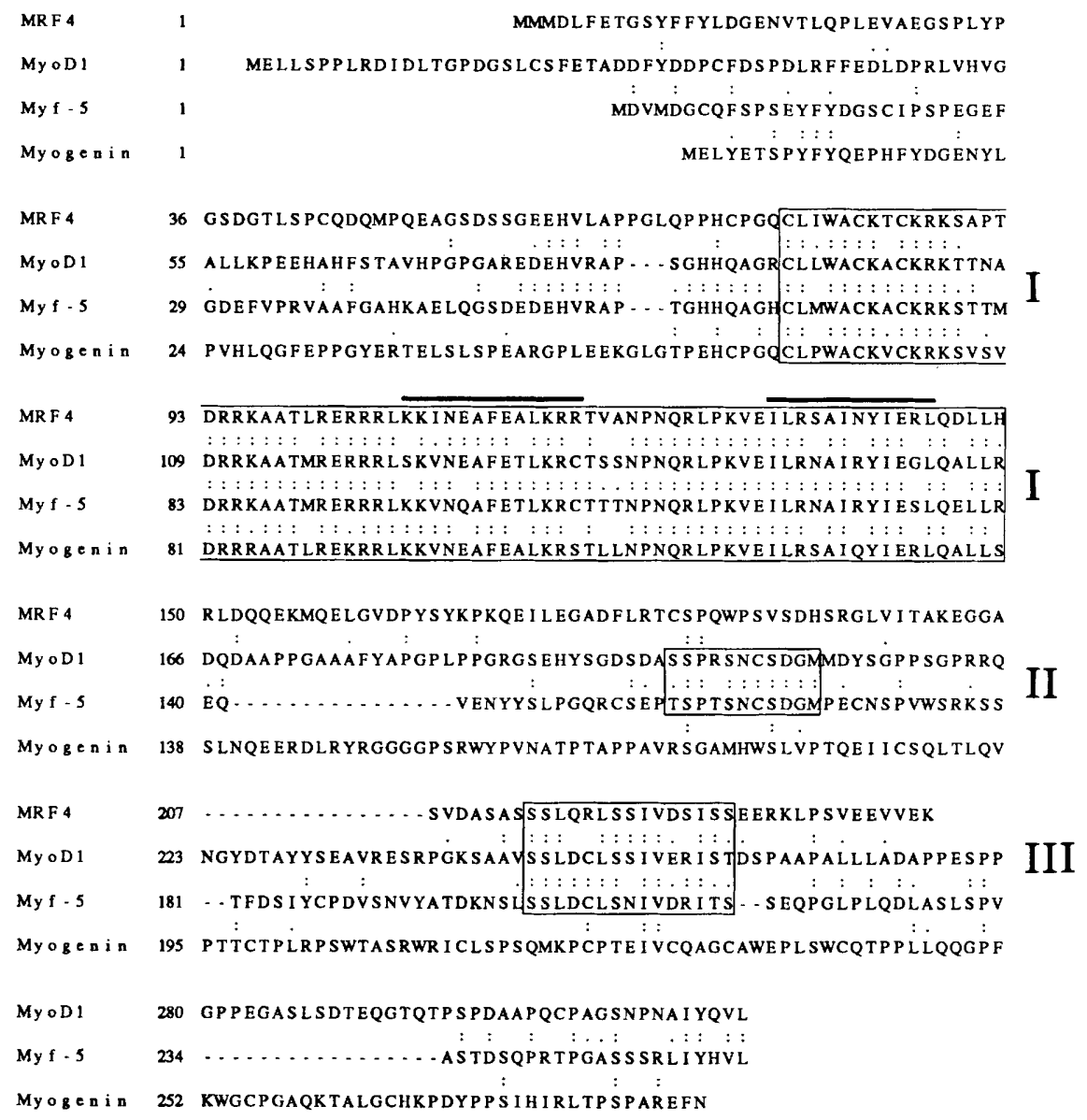

Figure 7. MRF4 is a member of a muscle regulatory factor gene family. The deduced amino acid sequences of the rat MRF4, mouse MyoD1 (Davis et al. 1987), human Myf-5 (Braun et al. 1989), and rat myogenin (Wright et al. 1989) cDNAs are aligned to achieve a maximum overall fit. Two dots between aligned residues indicate identity at that position, whereas a single dot indicates a conservative substitution. Boxes I, II, and III define three areas of similarity between the predicted protein sequences. MRF4, MyoD1, Myf-5, and myogenin share a highly conserved basic/myc-like domain (I). The two bars indicate the putative amphipathic helices of the HLH motif (Murre et al. 1989a,b) within this region. Region II (found in MyoD1 and Myf-5) and region III (found in MRF4, MyoD1, and Myf-5) are also conserved among members of this gene family.

The integrity of the basic/myc-like region in MyoD1 has been shown by Tapscott et al. (1988) to be essential for the conversion of $\mathrm{C} 3 \mathrm{H} 10 \mathrm{~T} 1 / 2$ cells to determined myoblasts, suggesting that this motif is required for each muscle regulatory factor to induce myogenic conversion in fibroblasts. The basic/myc-like region has also been identified in the products of genes that regulate specific growth and developmental events, including daughterless (da) (Caudy et al. 1988; Cronmiller et al. 1988), twist (Thisse et al. 1988), Enhancer of split (Klaembt et al. 1989), and achaete-scute (As-C) (Alonso and Cabrera 1988), the genes encoding the immunoglobulin enhancer-binding proteins, E12 and E47 (Murre et al. 1989a,b), the myc family of oncogenes (Battey et al. 1983; DePinho et al. 1987), and the 1yl-1 gene (Mellentin et al. 1989). Murre et al. (1989a) recently hypothesized that the conserved basic/myc-like domain found in each of these gene products forms an Helix-Loop-Helix (HLH) motif, which is essential for protein dimerization and DNA binding. Subsequent experiments from Murre and colleagues demonstrated that the immunoglobulin enhancer-binding proteins E12 and E47, in combination with other members of the HLH protein family, including MyoDl, As-C, and da, produce heterodimers (E12/MyoD1; E47/MyoD1; E12/As-C; E47/As-C; As-C/ da) that bind specifically to the $\kappa E 2$ enhancer element (Murre et al. 1989b). The role that HLH protein heterodimers have in regulating developmental events remains unclear, although these studies suggest that the precise regulation of lineage decisions may involve the interaction of ubiquitous (E12, E47, da) and tissue-specific (MyoD1, As-C) gene products.

At the present time, it is not known whether MRF4, MyoD1, myogenin, or Myf-5 similarly function as dimeric polypeptides in vivo. However, it is intriguing to speculate that homo- or heterodimer complexes consisting of the various members of this muscle regulatory factor family may control aspects of skeletal myogenesis. Experiments currently are in progress to determine whether the conserved regulatory domain found in 
MRF4, MyoD1, myogenin, and Myf-5 is able to function in different combinatorial patterns to precisely control specific myogenic events. If this model proves to be correct, it may suggest how a number of unique, yet related, proteins are used to orchestrate the developmental progression that culminates in the formation of mature skeletal muscle fibers.

One of the interesting features of MRF4 is its ability to activate (either directly or indirectly) other myogenic regulatory genes. C3H10T1/2 cells constitutively expressing the rat MRF4 cDNA convert to skeletal myoblasts and express the endogenous mouse MyoDl and myogenin genes. The converse is not true. MyoDl or myogenin expression in C3H10T1/2 cells is not sufficient to activate the endogenous MRF4 gene. The pattern of MRF4-induced expression of MyoDl and myogenin in converted C3H10T1/2 cells is identical, with mRNA accumulating only after cells have been induced to differentiate. Although this pattern was predicted for myogenin, it was unexpected for MyoD1, because control 23A2 and C2C12 myoblasts express high levels of MyoD1 (Vaidya et al. 1989). The myofiber-specific expression pattern for MyoDl observed in these studies is not a property unique to the C3H10T1/2 MRF4-\#7 cell line, because pooled C3H10T1/2 MRF4 cells and C3H10T1/2 myogenin clones similarly regulate MyoD1 expression. Additionally, because MyoD1, myogenin, and the contractile protein genes are corepressed by FGF (also see Vaidya et al. 1989), we believe that MyoDl, like myogenin, is normally expressed in myogenic cells only after mitogen removal. The expression of MyoD1 observed in $23 \mathrm{~A} 2$ and $\mathrm{C} 2 \mathrm{C} 12$ myoblasts is likely an anomaly associated with these established cell lines. In support of our hypothesis, recent studies from Montarras et al. (1989), using an inducible myogenic cell line, and Thayer et al. (1989), using a myogenin-transfected C3H10T1/2 cell line, have confirmed that MyoD1 expression in these cells is restricted to differentiated muscle fibers.

Preliminary studies from our laboratory have shown that MRF4, like MyoD1 (Lin et al. 1989; Weintraub et al. 1989), myogenin (Edmondson and Olson 1989), and Myf-5 (Braun et al. 1989), activates expression of muscle-specific promoters when transiently cotransfected into nonmyogenic cell types /K. Yutzey, S. Rhodes, and S. Konieczny, unpubl.). These experiments suggest that each muscle regulatory gene encodes a protein factor that is involved in the transcriptional regulation of the contractile protein gene set. Buskin and Hauschka (1989) and Lassar et al. (1989b) have reported that MyoD1 specifically binds to the mouse $M$-creatine kinase enhancer element and therefore likely plays a role in the expression of this muscle-specific gene product. Studies from our laboratory have shown that the individual members of the muscle regulatory factor gene family, although appearing to perform similar functions in a $\mathrm{C} 3 \mathrm{H} 10 \mathrm{~T} 1 / 2$ conversion assay, exhibit distinct and different properties with regard to the activation of specific contractile protein genes (K. Yutzey, S. Rhodes, and S. Konieczny, in prep.). The conserved HLH motif common to each gene product may be involved in the trans-activation of the contractile protein genes, as this motif is crucial for the DNA-binding activities associated with MyoDl (Lassar et al. 1989b) and with the immunoglobulin enhancer-binding proteins E12 and E47 (Murre et al. 1989a,b). The availability of cloned muscle regulatory factors should permit a detailed analysis of how these gene products function in regulating skeletal muscle development.

We and others predicted that a gene converting C3H10T1/2 cells to stable myogenic cell lineages would be involved directly in the myogenic determination process and should therefore be referred to as a "determination gene." From our initial experiments, we predicted that only one or, at most two, determination loci would be required to achieve this conversion (Konieczny and Emerson 1984). Surprisingly, five distinct gene products have been identified to date that accomplish this singular event; namely, the establishment of muscle lineages. In addition, several lines of evidence suggest that these regulatory factors function to activate the contractile protein gene set directly, implying that they play a dominant role in controlling terminal differentiation events. Evidence from our current studies showing that MyoD1 and myogenin are transcriptionally regulated by exogenous growth factors supports this hypothesis. If these genes are involved in terminal differentiation decisions, it is unclear why they also convert C3H10T1/2 cells to stable myogenic lineages. One possibility is that the expression of each of the muscle regulatory factor genes in C3H10T1/2 cells activates a master determination gene yet to be identified. This model predicts that a positive feedback mechanism coordinates the expression of the muscle regulatory factor genes, as well as the contractile protein gene set. The existence of such a feedback regulatory pathway also explains the ability of myogenic regulatory genes to autoregulate their expression (Edmondson and Olson 1989; Thayer et al. 1989) and the expression of other genes in this conserved gene family. It is now clear that the molecular mechanisms by which the muscle regulatory factor gene family controls skeletal myogenesis are very complex. Understanding these unique mechanisms will require the identification of putative DNA targets that are specific for each of these muscle regulatory factors.

\section{Materials and methods}

cDNA library screening

MRF4 was isolated by screening a rat soleus $\lambda$ gt 10 cDNA library with a mouse MyoDl cDNA probe (Davis et al. 1987), using standard procedures. Briefly, $3 \times 10^{5}$ plaques $1 \sim 25,000$ plaques $/ 150 \mathrm{~mm}$ plate) were transferred to nitrocellulose filters (Schleicher \& Schuell) and hybridized to a nick-translated MyoDl cDNA probe (sp. act. $\geqslant 1 \times 10^{8} \mathrm{cpm} / \mu \mathrm{g}$ ) at $65^{\circ} \mathrm{C}$ in $6 \times$ SSC ( $1 \times$ SSC is $150 \mathrm{~mm} \mathrm{NaCl}, 15 \mathrm{~mm} \mathrm{Na}$ citrate), $20 \mathrm{~mm}$ Tris$\mathrm{Cl}(\mathrm{pH} 7.6), 5 \times$ Denhardt's solution (Maniatis et al. 1982), 2 mM EDTA, $0.5 \%$ SDS, and $100 \mu \mathrm{g} / \mathrm{ml}$ denatured salmon sperm DNA. Hybridized filters were washed for $1 \mathrm{hr}$ at $60^{\circ} \mathrm{C}$ in $1 \times$ SSC, $0.2 \%$ SDS, and 2 mM EDTA and exposed to Kodak XAR film overnight. Isolate $\lambda c R S 4-1$ was chosen for further analysis 
because of its moderate hybridization to the MyoD1 probe. The 1244-bp EcoRI insert of this phage was purified and subcloned into pUC19 and into the expression vector pEMSVscribe $\alpha 2$ (Davis et al. 1987) for DNA sequencing and for expression studies. Secondary library screens using the $\lambda \mathrm{cRS} 4-1$ insert as a probe identified six additional positive phage, with the longest, $\lambda$ cRS6-4, being chosen for further analysis. The inserts contained within $\lambda \mathrm{cRS} 4-1$ and $\lambda \mathrm{cRS} 6-4$ represent MRF4 cDNA nucleotide positions +45 to +1288 and +1 to +1296 , respectively.

\section{Sequence analysis}

Nested deletions of the $\lambda$ cRS4- 1 insert were generated in both orientations using the unidirectional exonuclease III/mung bean nuclease method of Henikoff (1984). Double-stranded DNA from selected clones was sequenced with the Pharmacia dideoxy sequencing kit and $\left[\alpha^{-32} \mathrm{P}\right] \mathrm{dATP}(800 \mathrm{Ci} / \mathrm{mmole}$, Amersham). Regions in which deletions did not overlap were sequenced using synthesized oligonucleotide primers to determine the complete nucleotide sequence of both DNA strands. Similar strategies were used to sequence the extended $5^{\prime}$ and $3^{\prime}$ ends of the $\lambda$ cRS6-4 EcoRI insert. DNA and protein sequence analyses were performed using DNASIS and PROSIS software (LKB/Hitachi). Protein data bank searches were provided by the BIONET National Computer Resource for Molecular Biology. Hydropathy analyses were performed with the HPATH program of William Cramer (Purdue University).

\section{Southern hybridization}

Genomic DNA was isolated from L6 myoblasts (rat), HeLa cells (human), and C3H10T1/2 cells (mouse) by phenol/chloroform extractions and ethanol precipitations. DNA was digested to completion with excess restriction enzyme, electrophoresed through $0.75 \%$ agarose gels, transferred to nitrocellulose (Schleicher \& Schuell), and hybridized to random-primed cDNA probes (sp. act. $\geqslant 1 \times 10^{9} \mathrm{cpm} / \mu \mathrm{g}$ ). Hybridization conditions were the same as indicated for the library screenings, except that washes were in $0.1 \times \mathrm{SSC}, 0.2 \% \mathrm{SDS}$, and $2 \mathrm{mM}$ EDTA at $65^{\circ} \mathrm{C}$ for identical probe/target matches or in $0.3 \times$ SSC, $0.2 \%$ SDS, and $2 \mathrm{mM}$ EDTA at $65^{\circ} \mathrm{C}$ for cross-species hybridizations. All cDNA probes were full length except for MRF4 in which the $\lambda$ cRS4-1 insert $(+45$ to $+1288 \mathrm{bp}$ ) was used.

\section{RNA isolation and Northern hybridization}

RNA was isolated from cultured cells and from frozen tissues by acid guanidinium isothiocyanate/phenol/chloroform extraction and isopropanol precipitations (Chomczynski and Sacchi 1987). RNA samples were electrophoresed through $1.0 \%$ agarose/formaldehyde gels (Lehrach et al. 1977), transferred to GeneScreen nylon membranes (New England Nuclear/Du Pont), and hybridized to nick-translated or random-primed cDNA probes, as described above. In some instances, hybridized probes were removed from the filters by boiling membranes in $0.5 \%$ SDS, after which additional hybridizations were carried out. Probes cM113aR and cR165aR were used to detect the fast and slow TnI isotypes, respectively, as described by Koppe et al. (1989). The pAL15 probe was used as an internal control to demonstrate that equivalent amounts of RNA were loaded in each lane. The pAL15 probe detects an unknown mRNA species that appears to be constitutively expressed in most cell types (Bernlohr et al. 1984, 1985; Vaidya et al. 1989).

\section{Cell culture and DNA transfections}

C3H10T1/2, NIH-3T3, BALB/c 3T3, HeLa, COS-1, L6, BC3H1, $\mathrm{C} 2 \mathrm{C} 12$, and $\mathrm{L} 8$ cell lines were obtained from the American Type Culture Collection. The growth and differentiation properties of the myogenic cell lines 23A2 (Konieczny and Emerson 1984), Sol8 (Mulle et al. 1988), L8E63 (Kaufman et al. 1980), and L6J1-C (Ringertz et al. 1978) have been described previously. All cell lines were maintained in BME (basal medium Eagle, GIBCO), $15 \%$ fetal bovine serum, plus penicillin $(100 \mathrm{U} / \mathrm{ml})$ and streptomycin $(100 \mu \mathrm{g} / \mathrm{ml})$, with the exception of C3H10Tl/ 2, COS-1, HeLa, NIH-3T3, and BALB/c-3T3 cells, which were maintained in $10 \%$ fetal bovine serum. All myogenic cell lines, including C3H10T1/2 MRF4-\#7, C3H10T1/2 MyoDl-\#8, and C3H10T1/2 myogenin-\#1, were maintained at low cell densities and fed growth medium every $48 \mathrm{hr}$ to prevent the cells from differentiating. To induce myogenic differentiation, confluent cultures were fed ITS (Sigma), a chemically defined medium consisting of low-glucose Dulbecco's modified Eagle minimal medium (GIBCO), $5 \mu \mathrm{g} / \mathrm{ml}$ insulin, $5 \mu \mathrm{g} / \mathrm{ml}$ transferrin, $5 \mathrm{ng} / \mathrm{ml}$ selenium, and penicillin-streptomycin for $48 \mathrm{hr}$, as described previously (Yutzey et al. 1989). In some experiments, C3H10T1/2 MRF4-\#7 cells were treated with $10 \mathrm{ng} / \mathrm{ml}$ basic FGF ( $R+D$ Systems) as reported by Vaidya et al. (1989).

Cells were transfected transiently with MRF4, MyoDl, and myogenin cDNAs contained within the pEMSVscribea2 Maloney sarcoma virus LTR-driven expression vector (Davis et al. 1987), essentially as described by Yutzey et al. (1989). Briefly, $5 \times 10^{5} \mathrm{C} 3 \mathrm{H} 10 \mathrm{~T} 1 / 2$ cells were transfected with $5 \mu \mathrm{g}$ of the MRF4, MyoDl, or myogenin expression vectors. After $4 \mathrm{hr}$, transfected cells were glycerol-shocked for $2 \mathrm{~min}$ and fed fresh growth medium. The following day, cells were fed growth medium and, $24 \mathrm{hr}$ later, switched to ITS differentiation medium. After $48 \mathrm{hr}$ in ITS, cells were fixed for immunocytochemistry.

Stable cotransfections of C3H10T1/2 cells with pKO-neo and either the MRF4, MyoD1, or myogenin expression vectors were as described previously (Taparowsky et al. 1987; Konieczny et al. 1989). C3H10T1/2 cells $\left(5 \times 10^{5}\right)$ were seeded onto $100-\mathrm{mm}$ dishes. The following day, a calcium phosphate precipitate containing $25 \mu \mathrm{g}$ C3H10T1/2 genomic DNA, $30 \mathrm{ng}$ pKO-neo, and $10 \mu \mathrm{g}$ MRF4, MyoD1, or myogenin expression vector DNA was added per dish. After $4 \mathrm{hr}$, the precipitate was removed and the cultures were fed fresh medium. Twenty-four hours later, the cultures were split into five $100-\mathrm{mm}$ dishes in growth medium containing $400 \mu \mathrm{g} / \mathrm{ml}$ of the neomycin analog G418 (GIBCO). After $\sim 2$ weeks, individual clones were isolated, using glass cloning rings, and maintained in the presence of G418. In some instances, individual primary colonies were pooled and maintained as a single population. Cultures to be scored for myogenesis were fed ITS medium and allowed to differentiate for 48 hr prior to fixation and subsequent immunocytochemistry or Giemsa staining.

\section{Immunocytochemistry}

Cell cultures were rinsed twice in cold phosphate buffered saline (PBS) [13 mM NaCl, $0.15 \mathrm{mM} \mathrm{KH}_{2} \mathrm{PO}_{4}, 0.27 \mathrm{mM} \mathrm{KCl}, 0.8$ $\left.\mathrm{mM} \mathrm{Na} \mathrm{PO}_{4}(\mathrm{pH} 7.4)\right]$ and fixed in a $20: 2: 1$ solution of $70 \%$ ethanol, formalin, and glacial acetic acid for $1 \mathrm{~min}$ at $4^{\circ} \mathrm{C}$. Fixed cultures were rinsed five times in PBS and incubated with the anti-myosin mouse monoclonal antibody MF-20 (Bader et al. 1982). Following two rinses in PBS, cultures were treated with a biotinylated anti-mouse IgG secondary antibody. Immune complexes were visualized using the Vectastain $A B C$ reagent (Vector Labs, Burlingame, California) and photographed under bright light conditions. Unstained cells were visualized with phase-contrast microscopy. 


\section{Acknowledgments}

We thank Ken Hastings for generously supplying the soleus cDNA library and TnI probes; Andrew Lassar and Woody Wright for the MyoD1 and myogenin expression vectors, respectively, and for communicating results prior to publication; Vijak Mahdavi, Christian Pinset, and John Coleman for myoblast cell lines; Sonia Pearson-White for the analysis of the myd cell lines; Bill Cramer and David Overdier for computer programs; and David Pot for assistance with the Bionet search. We are very grateful for the excellent technical assistance of Shari Menke and Robyn Kline and thank Elizabeth Taparowsky and Ruthann Nichols for creative discussions and suggestions. S.J.R. was supported by a Purdue University David Ross Fellowship. This work was funded by grants to S.F.K. from the National Institutes of Health. The nucleotide sequence data reported in this paper have been submitted to GenBank and assigned the accession number M27151.

\section{References}

Alonso, M.C. and C.V. Cabrera. 1988. The achaete-scute complex of Drosophila melanogaster comprises four homologous genes. $E M B O$ /. 7: 2585-2591.

Bader, D., T. Masaki, and D.A. Fischman. 1982. Immunochemical analysis of myosin heavy chain during avian myogenesis in vivo and in vitro. J. Cell. Biol. 95: 763-770.

Battey, J., C. Moulding, R. Taub, W. Murphy, T. Stewart, H. Potter, G. Lenoir, and P. Leder. 1983. The human c-myc oncogene: Structural consequences of translocation into the IgH locus in Burkitt lymphoma. Cell 34: 779-787.

Bernlohr, D.A., M.A. Bolanowski, T.J. Kelly, Jr., and M.D. Lane. 1985. Evidence for an increase in transcription of specific mRNAs during differentiation of $3 \mathrm{~T} 3-\mathrm{L} 1$ preadipocytes. $J$. Biol. Chem. 260: 5563-5567.

Bernlohr, D.A., C.W. Angus, M.D. Lane, M.A. Bolanowski, and T. Kelly, Jr. 1984. Expression of specific mRNAs during adipose differentiation: identification of an mRNA encoding a homologue of myelin P2 protein. Proc. Natl. Acad. Sci. 81: 5468-5472.

Braun, T., G. Buschhausen-Denker, E. Bober, E. Tannich, and H.H. Arnold. 1989. A novel human muscle factor related to but distinct from $\mathrm{MyoDl}$ induces myogenic conversion in 10T1/2 fibroblasts. EMBO I. 8: 701-709.

Buskin, J.N. and S.D. Hauschka. 1989. Identification of a myocyte nuclear factor which binds to the muscle-specific enhancer of the mouse creatine kinase gene. Mol. Cell. Biol. 9: $2627-2640$.

Caudy, M., H. Vassin, M. Brand, R. Tuma, L.Y. Jan, and Y.N. Jan. 1988. daughterless, a Drosophila gene essential for both neurogenesis and sex determination has sequence similarities to myc and the achaete-scute complex. Cell 55: 10611067.

Cavener, D.R. 1987. Comparison of the consensus sequence flanking translational start sites in Drosophila and vertebrates. Nucleic Acids Res. 15: 1353-1361.

Chapman, A.B., D.M. Knight, B.S. Dieckmann, and G.M. Ringold. 1984. Analysis of gene expression during differentiation of adipogenic cells in culture and hormonal control of the developmental program. I. Biol. Chem. 259: 1554815555.

Chomczynski, P. and N. Sacchi. 1987. Single-step method of RNA isolation by acid guanidinium thiocyanate-phenolchloroform extraction. Anal. Biochem. 162: 156-159.

Cronmiller, C., P. Schedl, and T.W. Cline. 1988. Molecular characterization of daughterless, a Drosophila sex determi- nation gene with multiple roles in development. Genes Dev. 2: $1666-1676$.

Davis, R.L., H. Weintraub, and A.B. Lassar. 1987. Expression of a single transfected cDNA converts fibroblasts to myoblasts. Cell 51: 987-1000.

DePinho, R.A., E. Legouy, L.B. Feldman, N.E. Kohl, G.D. Yancopoulos, and Alt, F. W. 1986. Structure and expression of the murine N-myc gene. Proc. Natl. Acad. Sci. 83: 18271831.

Edmondson, D.G. and E.N. Olson. 1989. A gene with homology to the myc similarity region of MyoDl is expressed during myogenesis and is sufficient to activate the muscle differentiation program. Genes Dev. 3: 628-640.

Henikoff, S. 1984. Unidirectional digestion with exonuclease III creates targeted breakpoints for DNA sequencing. Gene 28: $351-359$.

Jung, A., A.E. Sippel, M. Grez, and G. Schutz. 1980. Exons encode functional and structural units of chicken lysozyme. Proc. Natl. Acad. Sci. 77: 5759-5763.

Kaufman, S.J., C.M. Parks, J. Bohn, and L.E. Faiman. 1980. Transformation is an alternative to normal skeletal muscle development. Exp. Cell Res. 125: 333-349.

Klaembt, C., E. Knust, K. Tietze, and J.A. Campos-Ortega. 1989. Closely related transcripts encoded by the neurogenic gene complex Enhancer of split of Drosophila melanogaster. $E M B O$ I. 8: 203-210.

Konieczny, S.F. and C.P. Emerson, Jr. 1984. 5-Azacytidine induction of stable mesodermal cell lineages from 10T1/2 cells: Evidence for regulatory genes controlling determination. Cell 38: 791-800.

Konieczny, S.F., A.S. Baldwin, and C.P. Emerson, Jr. 1986. Myogenic determination and differentiation of $10 \mathrm{~T} 1 / 2$ cell lineages: evidence for a simple genetic regulatory system. In Molecular biology of muscle development, UCLA Symposium on Molecular and Cellular Biology, (ed. C. Emerson, D. A. Fischman, B. Nadal-Ginard, and M.A. Siddiquil, Vol. 29, pp. 21-34. Alan R. Liss, New York.

Konieczny, S.F., B.L. Drobes, S.L. Menke, and E.J. Taparowsky. 1989. Inhibition of myogenic differentiation by the H-ras oncogene is associated with the down regulation of the MyoDl gene. Oncogene 4: 473-481.

Koppe, R.I., P.L. Hallauer, G. Karpati, and K.E.M. Hastings. 1989. cDNA clone and expression analysis of rodent fast and slow skeletal muscle troponin I mRNAs. I. Biol. Chem. 264: 14327-14333.

Kozak, M. 1987. An analysis of 5'-noncoding sequences from 699 vertebrate messenger RNAs. Nucleic Acid Res. 15: $8125-8148$.

Kyte, J. and R.F. Doolittle. 1982. A simple method for displaying the hydropathic character of a protein. I. Mol. Biol. 157: $105-132$.

Landschulz, W.H., P.F. Johnson, and S.L. McKnight. 1988. The leucine zipper: A hypothetical structure common to a new class of DNA binding proteins. Science 240: 1759-1764.

Lassar, A.B., B.M. Paterson, and H. Weintraub. 1986. Transfection of a DNA locus that mediates the conversion of $10 \mathrm{~T} 1 / 2$ fibroblasts to myoblasts. Cell 47: 649-656.

Lassar, A.B., M.J. Thayer, R.W. Overell, and H. Weintraub. 1989a. Transformation by activated ras or fos prevents myogenesis by inhibiting expression of MyoD1. Cell 58: 659667.

Lassar, A.B., J.N. Buskin, D. Lockshon, R.L. Davis, S. Apone, S.D. Hauschka, and H. Weintraub. 1989b. MyoD is a sequence-specific DNA binding protein requiring a region of myc homology to bind to the muscle creatine kinase enhancer. Cell 58: 823-831. 
Lehrach, H., D. Diamond, J.M. Wozney, and H. Boegtker. 1977. RNA molecular weight determinations by gel electrophoresis under denaturing conditions, a critical reexamination. Biochemistry 16: 4743-4750.

Lin, Z.-Y., C.A. Deschene, J. Eldridge, and B.M. Paterson. 1989. An avian muscle factor related to MyoD1 activates musclespecific promoters in nonmuscle cells of different germlayer origin and in BrdU-treated myoblasts. Genes Dev. 3: 986-996.

Maniatis, T., E.F. Fritsch, and J. Sambrook. 1982. Molecular cloning: A laboratory manual. Cold Spring Harbor Laboratory, Cold Spring Harbor, New York.

Mellentin, J.D., S.D. Smith, M.L. Cleary. 1989. lyl-1, a novel gene altered by chromosomal translocation in $\mathrm{T}$ cell leukemia, codes for a protein with a helix-loop-helix DNA binding motif. Cell 58: 77-83.

Montarras, D., C. Pinset, J. Chelly, A. Kahn, and F. Gros. 1989. Expression of MyoDl coincides with terminal differentiation in determined but inducible muscle cells. EMBO J. 8: 2203-2207.

Mulle, C., P. Benoit, C. Pinset, M. Roa, and J.-P. Changeux. 1988. Calcitonin gene-related peptide enhances the rate of desensitization of the nicotinic acetylcholine receptor in cultured mouse muscle cells. Proc. Natl. Acad. Sci. 85: 5728-5732.

Murre, C., P. Schonleber McCaw, and D. Baltimore. 1989a. A new DNA binding and dimerization motif in immunoglobulin enhancer binding, daughterless, MyoD and myc proteins. Cell 56: 777-783.

Murre, C., P. Schonleber McCaw, H. Vaessin, M. Caudy, L.Y. Jan, Y.N. Jan, C.V. Cabrera, J.N. Buskin, S.D. Hauschka, A.B. Lassar, H. Weintraub, and D. Baltimore. 1989b. Interactions between heterologous helix-loop-helix proteins generate complexes that bind specifically to a common DNA sequence. Cell 58: 537-544.

Ordahl, C.P. 1986. The skeletal and cardiac $\alpha$-actin genes are coexpressed in early embryonic striated muscle. Dev. Biol. 117: $488-492$.

Pinney, D.F., S.H. Pearson-White, S.F. Konieczny, K.E. Latham, and C.P. Emerson, Jr. 1988. Myogenic lineage determination and differentiation: Evidence for a regulatory gene pathway. Cell 53: 781-793.

1989. Evidence for a regulatory gene pathway of myogenic determination and differentiation. In Cellular and molecular biology of muscle development, UCLA Symposium on Molecular and Cellular Biology, (ed. L.H. Kedes and F.E. Stockdale), Vol. 93, pp. 67-74. Alan R. Liss, New York.

Reznikoff, C.A., D.W. Brankow, and C. Heidelberger. 1973. Establishment and characterization of a cloned line of $\mathrm{C} 3 \mathrm{H}$ mouse embryo cells sensitive to postconfluence inhibition of division. Cancer Res. 33: 3231-3238.

Ringertz, N.R., U. Krondahl, and J.R. Coleman. 1978. Reconstitution of cells by fusion of cell fragments. I. Myogenic expression after fusion of minicells from rat myoblasts (L6) with mouse fibroblast (A9) cytoplasm. Exp. Cell Res. 113: $233-246$.

Sassoon, D.A., I. Garner, and M. Buckingham. 1988. Transcripts of $\alpha$-cardiac and $\alpha$-skeletal actins are early markers for myogenesis in the mouse embryo. Development 104: 155-164.

Sassoon, D., G. Lyons, W.E. Wright, V. Lin, A. Lassar, H. Weintraub, and M. Buckingham. 1989. Expression of two myogenic regulatory factors, myogenin and MyoD1, during mouse embryogenesis. Nature 341: 303-307.

Taparowsky, E.J., M.L. Heaney, and J.T. Parsons. 1987. Oncogene-mediated multistep transformation of $\mathrm{C} 3 \mathrm{H} 10 \mathrm{~T} 1 / 2$ cells. Cancer Res. 47: 4125-4129.

Tapscott, S.J., R.L. Davis, M.J. Thayer, P.-F. Cheng, H. Weintraub, and A.B. Lassar. 1988. MyoDl: A nuclear phosphoprotein requiring a $m y c$ homology region to convert fibroblasts to myoblasts. Science 424: 405-411.

Taylor, S.M. and P.A. Jones. 1979. Multiple new phenotypes induced in 10T1/2 and 3T3 cells treated with 5-azacytidine. Cell 17: 771-779.

1982. Changes in phenotypic expression in embryonic and adult cells treated with 5-azacytidine. J. Cell. Physiol. 111: $187-194$.

Thayer, M.J., S.J. Tapscott, R.L. Davis, W.E. Wright, A.B. Lassar, and H. Weintraub. 1989. Positive autoregulation of the myogenic determination gene MyoDl. Cell 58: 241248 .

Thisse, B., C. Stoetzel, C. Gorostiza-Thisse, and F. PerrinSchmidt. 1988. Sequence of the twist gene and nuclear localization of its protein in endomesodermal cells of early Drosophila embryos. EMBO J. 7: 2175-2183.

Vaidya, T., S.J. Rhodes, E.J. Taparowsky, and S.F. Konieczny. 1989. Fibroblast growth factor and transforming growth factor- $\beta$ repress expression of the myogenic regulatory gene, MyoD1. Mol. Cell. Biol. 9: 3576-3579.

Weintraub, H., S.J. Tapscott, R.L. Davis, M.J. Thayer, M.A Adam, A.B. Lassar, and A.D. Miller. 1989. Activation of muscle-specific genes in pigment, nerve, fat, liver, and fibroblast cell lines by forced expression of MyoD. Proc. Natl. Acad. Sci. 86: 5434-5438.

Wright, W.E., D.A. Sassoon, and V.K. Lin. 1989. Myogenin, a factor regulating myogenesis, has a domain homologous to MyoD. Cell 56: 607-617.

Yutzey, K.E., R.L. Kline, and S.F. Konieczny 1989. An internal regulatory element controls troponin I gene expression. Mol. Cell. Biol. 9: 1397-1405. 


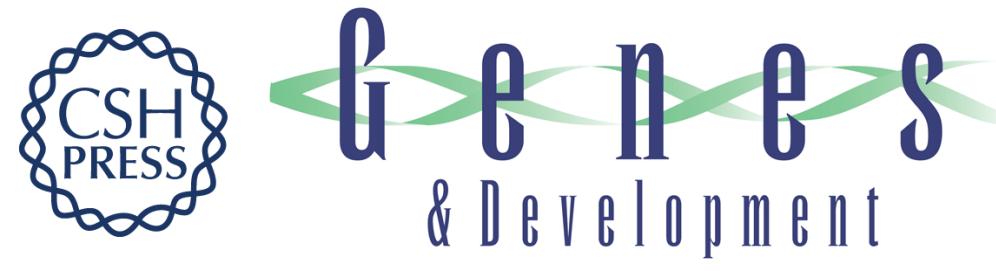

\section{Identification of MRF4: a new member of the muscle regulatory factor gene family.}

S J Rhodes and S F Konieczny

Genes Dev. 1989, 3:

Access the most recent version at doi:10.1101/gad.3.12b.2050

References This article cites 51 articles, 19 of which can be accessed free at:

http://genesdev.cshlp.org/content/3/12b/2050.full.html\#ref-list-1

License

Email Alerting

Service

Receive free email alerts when new articles cite this article - sign up in the box at the top right corner of the article or click here.



